\title{
Family-related demands, positive orientation, coping strategies and family satisfaction: A mediation model
}

\author{
Joana M. Suta, PhD \\ Member of the Association of Psychologists of Lazio, Rome, Italy
}

\begin{abstract}
This study investigates how gradual social change may affect subjective well-being (SWB) in the family domain, for example how it impacts family satisfaction. Individuals are active agents who use personal resources and coping strategies to protect their SWB from the effects of social change. Specifically, we predict that family demands affect SWB negatively, whereas positive orientation and coping strategies have a protective role. In a sample of 261 young Italian adults, family-demands associated with social changes were found to have negative effects that could only be reduced from having a positive orientation. Furthermore, confirming the motivational theory of lifespan development, problem-focused strategies were beneficial for family satisfaction to the extent that they represent an adaptation response to demands associated with social changes.
\end{abstract}

Keywords: Social changes, family-related demands, positive orientation, coping strategies and family satisfaction.

\section{Introduction}

The accumulation of negative manifestations of social changes represents a risk factor for individual adaptation and subjective well-being (SWB). "Social change is defined as a more or less rapid and comprehensive change of societal structures and institutions, including changes to the political, economic, and cultural frameworks of a society" (Grumer et al., 2013, pg, 1268). The demands associated with social changes are perceived as a mismatch between age-related habits and emerging developmental life tasks (Silbereisen et al., 2006, 2010).The current study stems from the theoretical framework of Silbereisen and colleagues, and aims to understand how gradual social changes can affect family life and SWB of young Italian adults.

Italy is a low birth rate country, with its rate dropping from 2.67 in 1965 to 1.32 in 2010, due to the high cost of living, as well as both insufficient and expensive childcare services. ISTAT (2012) has estimated that $41.9 \%$ of young Italian adults ranging from 25-29 years of age are unable to afford the cost of living on their own, and are still living with their parents. Delayed time of forming a new family and having a lower birth rate, have serious consequences for the future of social security systems.

\section{Psychological Resources, Coping Strategies and SWB}

The differences in inter-individual resources and skills considerably influence the effects of gradual social changes on SWB and the activation of coping strategies (Pinquart \& Silbereisen, 2004). The positive orientation may be specifically effective for studying the role of individual resources for coping with the demands of social changes.

The term positive orientation has been used by Caprara \& Colleagues (2009) to denote the basic tendency of individuals to evaluate life and difficulties more positively. Positive orientation determines the effect of social changes on SWB using control strategies. According to the Model of Social Change and Human Development (Silbereisen et al., 2010), the motivational life span theory of control (Heckhausen et al., 2010) represents an adequate theoretical framework to classify and evaluate how an individual deals with the demands of social changes. This theory consists of two basic strategies of coping: a) active: in which people engage with the issue and try to control it; and b) disengaged: in which people view demands to be uncontrollable. 
Silbereisen and colleagues have extensively investigated the negative effects of perceived family demands on individual SWB (Pinquart \& Silbereisen, 2008; , Grumer et al., 2013). Family satisfaction may represent an important indicator of family-related SWB, which can be affected negatively by social changes. It represents a global variable of family functioning which includes: the level of support received, the solutions to family problems, the quality of time spent together, and the grade of independence within the family (Caprara et al., 2005).

\section{Objective and Hypotheses}

This study explored how family-related demands can affect the relationship between positive orientation and family satisfaction, both directly through, and mediated by, coping strategies. In addition, we also posited a direct effect of perceived family demands on coping strategies and family satisfaction. Thus, we hypothesized that perceived family demands is a variable that affects all others simultaneously.

We hypothesized that:

$\mathrm{H} 1$ : Family demands can influence the role of positive orientation on family satisfaction and coping strategies. These demands may exert a negative impact on positive orientation. Both coping strategies of focusing and distancing are activated by family demands. Also, we hypothesize that family demands will have a negative impact on family satisfaction.

H2: Positive orientation impacts coping strategies with positive effects on problem-focused coping and negative effects on distancing strategies. Its influence reduces the negative effect of demands on family satisfaction.

H3: Problem and distancing coping strategies mediate family satisfaction, have negative effects on family demands, and have protective effects on positive orientation.

\section{Methods}

Participants and measures:

The participants in this study were 261 young adults, residents of Rome, Italy. They were 24 to 29 years old (M = 25.85 , DS $=1.49$ ) with $56.7 \%$ females. Approximately $70 \%$ of participants had at least a high school diploma. Ninety percent of male and $78 \%$ of female participants still lived with their original families.

The instruments of this study were part of a battery that the participants completed individually, and consisted of:

i) Perceived family-related demands associated with social change; this 6 item scale measures how social changes affect an individual in their family life domain (Silbereisen et al. 2006);

ii) Coping strategies with perceived demands family related due to social change (Silbereisen et al., 2006, 15 items). This scale measures two coping strategies: problem-focused and problem-distancing.

iii) Coping Problem-focused strategy is measured by the means of three subscales of selective primary control, compensatory primary control and selective secondary control (SSC); while Coping Problem-distancing strategy is measured through two subscales of Compensatory secondary control I and Compensatory secondary control II. Each subscale is further measured by three items.

iv) As a measure of scale of self-esteem, Rosenberg's (1965) scale (RSES) containing 10 items was used measuring state self-esteem by asking respondents to reflect on their current feelings; the Life Satisfaction Scale by Diner et al. (1985) measures satisfaction with life as whole (SWLS) containing 5 items; and Optimism-Revised Scale by Scheier et al. (1994), (LOT-R), containing 6 items measuring dispositional optimism towards life. 
v) The Family Satisfaction Scale Revised (Olson, 1982) is an instrument containing six items assessing two major dimensions of Olson's Circumplex Model of family functioning, adaptability and cohesion. Four items were used for this study.

\section{Results}

Family demands, positive orientation, coping strategies and family satisfaction

Some of the variables tested show asymmetries and kurtosis values that exceed $|1|$. We tested the hypothesized relations among variables by using M-plus 5 (Muthén \& Muthén, 1998-2007) with maximum likelihood estimation with robust standard errors (MLR). Mediated effects were calculated using the procedures outlined by MacKinnon et al. (2002) and formal mediation test by using bootstrapped confidence interval.

The hypothesized structural model

The variables analyzed were defined as following:

Family demands were defined as a cumulative represented index by the sum of the items that were strongly (6) or very strongly (7) endorsed by the respondent. Positive orientation was defined as a latent variable loaded by three indicators: self-esteem, life satisfaction and optimism, which in turn were posited as the mean of the items of the respective scales. The latent variable of problem-focused strategy was defined by three indicators: selective primary, compensatory primary and secondary primary controls, respectively. Problem-distancing was defined in a similar way, as a latent factor defined by two indicators: Compensatory secondary control I and Compensatory secondary control II. Each indicator of the two latent coping variables strategies was computed as the mean of its three items. The latent variable of family satisfaction was defined by using four of the six indicators of the revisedfamily satisfaction scale.

To take into account the role of family-related demands, we included this variable as a covariate, influencing all other variables included in the study. Positive orientation, coping strategies and family satisfaction were predicted by family-related demands. Coping strategies and family satisfaction were predicted in turn by positive orientation. Lastly, both problem-focused and problem-distancing coping strategies used, as hypothesized, mediated the effect of positive orientation on family satisfaction.

Structural equation analysis

The hypothesized model fits the data well: $\chi 2(56)=121,094 p=.001$, CFI $=94, T L I=.91$, RMSEA $=.07$ (.05-.08). Family demands negatively predicted positive orientation $(-.21 ; p<.001)$, and positively predicted problem-focused coping $(.31 ; p<.001)$. Family demands contributed directly to problem distancing coping $(-.14 ; p<.01)$ but failed to contribute directly to family satisfaction $(-.03 \mathrm{n} . \mathrm{s})$. In turn, positive orientation predicted positively problemfocused coping $(.32 ; p<.001)$ and family satisfaction $(.34 ; p<.001)$, and negatively problem-distancing strategies ($.34 ; p<.001)$.

In order to test mediation more formally, we computed confidence intervals around the significant coefficients for the indirect effects, using the bootstrap (with 1,000 replications) method as implemented in Mplus 5 (MacKinnon et al., 2002, 2004). Below, we briefly present the significant mediated effects.

Family Demands

The mediated effect of demands on family satisfaction through problem-focused strategies was statistically significant with associated unstandardized coefficients $\beta=.06$. The confidence intervals for this indirect path coefficient were not including zero (i.e. $95 \% \mathrm{Cl}$ : from. 005 to 106). The mediated effect of demands through 
positive orientation on family satisfaction was statistically significant with associated unstandardized coefficient $\beta$ $=-.06$. The confidence intervals for this indirect path were not including zero (i.e. $95 \% \mathrm{Cl}$ : from -.112 to -.010 ).

Positive Orientation

A mediated effect of positive orientation on family satisfaction through problem-focused coping strategies was significant, with an associated unstandardized coefficient of $\beta=.059$ and an associated interval confidence which did not include zero (i.e. $95 \% \mathrm{Cl}$ : from.009 to.110).

The variance explained by the model for each dependent variable was: $26.5 \%$ for problem-focused coping strategies and $11 \%$ for problem-distancing coping strategies. For positive orientation the variance explained was $5 \%$ and for family satisfaction was $28 \%$.

\section{Discussion, Conclusion and Implications for Youth Integration}

This study demonstrates the importance of the construct of positive orientation, operationalized as the interplay of optimism, life satisfaction and self-esteem. The perceived family-related demands associated with social change have a negative impact on structured resources, representing a threat for SWB. Positive orientation function filters out the negative effect of family related-demands by deactivating problem-distancing strategies and, consequently, preserving global family satisfaction.

The main interesting facet of the results of this study is the positive indirect effect of family-related demands over family satisfaction. The complexity of this relationship opens the way to new discussion and conclusions. First of all, family related demands represent developmental task challenges related to specific life stages in this domain (e.g. to create own family or to have a child). This domain continues to have importance and a strong normative power for the young adults in our sample. Secondly, young adults face these demands by activating coping strategies as a way to find solutions for their problems. This is a demonstration of what Heckhausen (2010) called "primacy to primary control" of the human being. By exerting primary control, young adults are engaged and motivated to attain their developmental task. The relevance of this study exploring subjective well-being as a form of family satisfaction, was that this variable was found to be a powerful resource for young adults coping with developmental tasks over time. For future, longitudinal studies would need to be designed in order to evaluate this hypothesis more accurately.

Implications

The current Italian social security system needs a thorough of the adopted strategies to devise such responsive processes that can be more helpful to its youth. The promotion of policies that encourage positive vision and proactive behavior in young adults can lead them to a better quality family life and eventually can contribute to a better collective well-being.

\section{References}

Caprara, G. V, Fagnani, C., Alessandri, G., Steca, P., Gigantesco, A., Cavalli Sforza, L. et al. (2009). Human optimal functioning: The genetics of positive orientation towards self, life, and the future. Behaviour Genetics, 39, 277284. doi:10.1007/s10519-009-9267-y

Caprara, G., Pastorelli, C., Regalia, C., Scabini, E., Bandura, A. (2005). Impact of Adolescents' Filial Self-Efficacy on Quality of Family Functioning and Satisfaction. Journal of research on adolescence,15 (1), 71-97. doi:

10.1037/1040-3590.20.3.227

Carver, C. S., Scheier, M. F., Weintraub, J.K. (1989). Assessing coping strategies: A theoretically based approach. Journal of Personality and Social Psychology, 56, 267-283. doi: http://dx.doi.org/10.1037/0022-3514.56.2.267 
Diener, E., Emmons, R.A., Larsen, R.J., \& Griffin, S. (1985). The satisfaction with life scale. Journal of Personality Assessment, 49, 71-75. doi: 10.1207/s15327752jpa4901_13

Grümer, S., Silbereisen, R. K., Heckhausen, J. (2013). Subjective well-being in times of social change: Congruence of control strategies and perceived control. International Journal of Psychology. doi:

http://dx.doi.org/10.1080/00207594.2012.744839

Heckhausen, J., Wrosch, C., \& Schulz, R. (2010). A motivational theory of lifespan development. Psychological Review, 117, 32-60. doi: 10.1037/a0017668

ISTAT (Istituto Nazionale di Statistica). (2012). Rapporto annuale. La situazione del Paese (National Institute of Statistics. Annual report. The situation of the country). retrieved from http://www.istat.org

MacKinnon, D. P., Lockwood, C. M., Hoffman, J. M., West, S. G., \& Sheets, V. (2002). A comparisons of methods to test mediation and other intervening variable effects. Psychological Methods, 7, 83-104.

MacKinnon, D. P., Lockwood, C. M., \& Williams, J. (2004). Confidence limits for the indirect effect: Distribution of products and resampling methods. Multivariate Behavioral Research, 39, 99-128. doi:10.1037/1082989X.7.1.83

Muthén, L.K. and Muthén, B.O. (1998-2007). Mplus User’s Guide. Fifth Edition. Los Angeles, CA: Muthén \& Muthén.

Olson, D., \& Wilson, R. (1982). Family satisfaction scale. In D. H. Olson, H. I. McCubbin, H. Barnes, A. Larsen, M. Muxen, \& M. Wilson (eds.), Family inventories (pp. 89-103). Minnesota: University of Minnesota.

Pinquart, M., Silbereisen, R. (2004). Human development in times of social change: Theoretical considerations and research needs, International Journal of Behavioral Development,28 (4), 289-298. doi:

10.1080/01650250344000406

Pinquart, M. \& Silbereisen, R.K. (2008). Coping with increased uncertainty in the field of work and family life. International Journal of Stress Management, 15, 209-221. doi: http://dx.doi.org/10.1037/a0029249

Rosenberg, M. (1965), Society and the adolescent self-image, Princeton University Press, Princeton, NJ.

Silbereisen, R. K., Pinquart, M., Reitzle, M., Tomasik, M. J., Fabel, K., \& Grümer, S. (2006). Psychosocial resources and coping with social change (SFB 580 Mitteilungen). Jena: Sonderforschungsbereich 580. Gesellschaftliche Entwicklungen nach dem Systemumbruch. Diskontinuität, Tradition und Strukturbildung.

Silbereisen, R. K., Pinquart, M. \& Tomasik, M. (2010). Demands of social change and psychosocial adjustment: Results from the Jena study. In R. K. Silbereisen \& X. Chen (eds.), Social change and human development: Concepts and results. London: Sage 